\title{
99m Tc-MDP Bone Scan in Lung Cancer: Predilection Sites for Metastasis
}

Shamim M F Begum, Zeenat Jabin, Rahima Perveen, Nasreen Sultana, Laila S Banu

National Institute of Nuclear Medicine and Allied Sciences, BSMMU, Dhaka

Address for Correspondences: Prof. Dr. Shamim Momtaz Ferdousi Begum, Professor and Head Nuclear Nephrology Division, National Institute of Nuclear Medicine \& Allied Sciences, BAEC

Email: pragyna06@yahoo.com, telephone: +880-2-9665912, mobile +880-1711849903

\begin{abstract}
Introduction: Bone scan with ${ }^{99 \mathrm{~m}}$ Tc-MDP is a commonly used procedure for evaluation of bone metastases because of its high sensitivity, availability, and relatively low cost. The predilection sites for bone metastasis in patients particularly with lung cancers were investigated in this study.
\end{abstract}

Methods: The study was done at the National Institute of Nuclear Medicine and Allied Sciences (NINMAS) between January 2013 and June 2014. A total of 123 patients with lung cancers who had whole body scintigraphy with ${ }^{99 \mathrm{~m}}$ Tc-MDP were studied. The bone scans were interpreted by experienced Nuclear Medicine physicians and the predilection sites with pattern of skeletal metastasis were analyzed.

Results: Among the 123 (m/f: 104/19) cases studied, 99 (80.5\%) patients had bone metastasis. Solitary metastatic lesion was detected in $18.2 \%$ cases, multiple lesions in $59.6 \%$ cases and extensive metastases were noted in $18.2 \%$ cases. Features of hypertrophic pulmonary osteoarthopathy were present in $4 \%$ cases. The predilection sites for metastases from lung cancer appear to be in the ribs $(75 \%$ cases) followed by spines $(54 \%$ cases) and pelvis (23\% cases). In total 595 metastatic lesions were detected, among them $469(78.8 \%)$ were distributed in axial skeleton and $126(21.2 \%)$ were in appendicular skeleton. Metastatic involvement was higher in axial skeleton comparing to the appendicular skeleton and the difference was statistically significant $(Z=13.99, \quad P<0.001)$. Similarly metastatic lesions detected on right side of body were 235 in number and on left side of the body were 189 in number. This difference of distribution between right and left side was also found to be statistically significant $(Z=2.218, p<0.002)$.

Conclusion: Bone metastasis is very common in patients with lung cancer. The predilection site for metastasis was the axial skeleton, which had statistically higher involvement than appendicular skeleton. Distributions of metastatic bone lesions were higher in ribs followed by vertebrae and pelvis. Significant difference was observed in the distribution of metastasis between the right and left side of body.

Key words: MDP (methylene diphosphonate), Lung cancer

\section{INTRODUCTION}

Radionuclide bone scan with ${ }^{99 \mathrm{~m}}$ Tc-MDP is still widely used in this era of positron emission tomography computed tomography (PET-CT) for detection of skeletal metastasis in patients with various tumoral entities. It is highly accurate, simple to perform, very cost effective and easily available at all nuclear medicine centers. Although bone scan is less specific for bone metastases, it helps the physician to narrow the diagnostic differentials by assessing the pattern of distribution of metastasis through bone scan findings $(1,2)$. Skeletal involvement from malignant tumors of the breast, prostate and lung is a common clinical occurrence found in about $30 \%$ to $70 \%$ cases at presentation or during follows up (3).

In this study we specifically focused on lung cancer, which is the commonest male cancer in Bangladesh, accounting for about $28.39 \%$ of all cancers (4). The incidence of bone metastasis in patients with lung cancer though common is quite variable. The frequency of metastases and rate of detection depends upon the type of primary malignancy, diagnostic tools, duration and followup of the disease. It is also related to the specific study population. High rate of detection of unsuspected distant metastases by advanced diagnostic methods such as PET-CT reports the incidence of metastasis from lung cancers to be about $20 \%$ to $40 \%$ cases (5). Bone involvement significantly affects prognosis and is related to the number of bone metastases. Treatment for cancers with limited disease is usually surgery with combination therapy for advanced cases. In nonsmall-cell lung cancer, bone metastasis is used for clinical staging of the disease and in selecting patients for surgical resection. 
Hence detection of bone metastasis is clinically very significant for clinical staging, treatment planning, and prognosis and follow up of the disease $(6,7)$. The objective of the present study was to examine the distribution pattern of bone metastases on ${ }^{99 \mathrm{~m}} \mathrm{Tc}$ MDP-bone scintigraphy in patients with lung cancer.

\section{MATERIALS AND METHODS}

This retrospective study was carried out at the National Institute of Nuclear Medicine and Allied Sciences (NINMAS), Dhaka, from January 2013 to June 2014. All the patients were referred for bone scan at NINMAS, having definitive clinical and/or histo-pathologically proven diagnosis of lung cancer. We included a total of 123 patients (104 male and 19 females, age range 30-85 years) in this study. Relevant clinical history and related investigations were recorded. Whole body bone scan was performed after intravenous injection of Tc $99 \mathrm{~m}$ MDP using Siemens E-CAM dual head gamma camera. Standard scans both in anterior and posterior projections of the whole body were obtained with spot views wherever necessary. Images of all patients were reviewed and interpreted by at least two experienced nuclear medicine specialists. During interpretation all available clinical information were taken into account. The reviewed scan results were correlated with previous findings and compared to available radiographs and results of other imaging.

Bone scans were considered as positive for metastatic lesions when increased uptake of radioactivity as per established criteria for metastasis was noted. For ribs: increased radiotracer uptake in linear form, in vertebrae: uptake in posterior aspect of body, pedicle or extensive vertebral involvement; lesions with intense uptake; multiple site involvement; scrambled pattern; decreased uptake due to osteolytic lesion or necrosis (not to be bone cyst) were considered as metastases. Increased tracer uptake due to known disorders like degenerative or benign bone changes was excluded. Absence of abnormal tracer uptake in bone due to metastasis was considered as negative scan for metastasis.

The metastasis was grouped as solitary bone metastasis, multiple metastases (up to five lesions), extensive metastasis (more than five lesions) and hypertrophic pulmonary osteoarthopathy. The lesions were also assessed by the pattern of distributed on left side and right side of the body.

The involved sites of metastases were divided in following groups:

1. Axial Skeleton - ribs, spines, sternum and skull

2. Appendicular Skeleton - a) pelvic girdle - pelvis, shoulder joint, sacroiliac joint, scapulae

b) limbs - femur, humerus and tibia.

The recorded data were statistically analyzed and initially expressed as frequencies and percentages of involvement of particular anatomical regions. Z-test was used for statistical analysis, $\mathrm{p}<0.05$ was considered as statistically significant difference.

\section{RESULTS}

Among the 123 (m/f: 104/19) cases (Table-1), 99 patients had positive bone scan for metastasis and $24(19.5 \%)$ cases had no metastasis. The overall rate of bone metastasis was $80.5 \%$ (Table-2). Solitary lesion was detected in $18.2 \%$ cases, multiple metastases in $59.6 \%$ cases and extensive metastases in $18.2 \%$ cases. Features of hypertrophic pulmonary osteoarthopathy were present in $4 \%$ cases (Table-3). Distributions of bone metastases from lung cancer were frequent in ribs ( $75 \%$ cases) followed by spines (54\% cases) and pelvis (23\% cases). Dorsal spines were found to be more involved (Table 4 and Table 5). In total 595 metastatic lesions were detected, among them 469 (78.8\%) were distributed in axial skeleton and 126 $(21.2 \%)$ in appendicular skeleton. Metastatic involvement was higher in axial skeleton comparing to the appendicular skeleton and the difference was statistically significant $(Z=13.99$, $\mathrm{p}<0.001)$ as shown in Table -6 . 
Similarly metastatic lesions detected on right side of body were 235 in number and on left side of the body it was189 in number. This difference of distribution between right and left side was statistically significant $(Z=2.218, \mathrm{p}<0.002)$ shown in Table-7.

Table 1: Sex distribution of the patient (n-123)

\begin{tabular}{|c|c|c|}
\hline Sex & Frequency & Percentage \\
\hline Male & 104 & 84.6 \\
\hline Female & 19 & 15.4 \\
\hline Total & 123 & 100.0 \\
\hline
\end{tabular}

Table-2: Frequency and Percentage of Bone Scan findings $(n=123)$

\begin{tabular}{|l|l|l|}
\hline Bone scan findings & Frequency & Percentage \\
\hline Positive bone scan & 99 & 80.5 \\
\hline Negative bone scan & 24 & 19.5 \\
\hline Total & 123 & 100.0 \\
\hline
\end{tabular}

Table 3: Type of metastasis $(n=99)$

\begin{tabular}{|l|c|c|}
\hline Type of metastasis & Frequency & Percentage \\
\hline Solitary bone metastasis & 18 & 18.2 \\
\hline Multiple Metastasis & 59 & 59.6 \\
\hline Extensive metastasis & 18 & 18.2 \\
\hline $\begin{array}{l}\text { Hypertrophic Pulmonary } \\
\text { Osteoarthropathy }\end{array}$ & 4 & 4.0 \\
\hline Total & 99 & 100.0 \\
\hline
\end{tabular}

Table 4: Number and Percentage of Anatomical distribution of lesions $(n=595)$

\begin{tabular}{|l|c|c|}
\hline Site & No of lesion & Percentage \\
\hline Ribs & 224 & 37.6 \\
\hline Spine & 207 & 34.8 \\
\hline Pelvic & 47 & 7.9 \\
\hline
\end{tabular}

Table 5: Spinal distribution $(n=207)$

\begin{tabular}{|l|c|c|}
\hline Spine & Frequency & Percentage \\
\hline Cervical Spine & 28 & 13.5 \\
\hline Dorsal Spine & 99 & 47.8 \\
\hline Lumbar Spine & 65 & 31.4 \\
\hline Sacrum & 15 & 7.3 \\
\hline Total & 207 & 100.0 \\
\hline
\end{tabular}

Table 6: Distribution of Metastases by skeleton $(\mathrm{n}=\mathbf{5 9 5})$

\begin{tabular}{|l|c|c|}
\hline Skeletal & No of lesion & Percentage \\
\hline Axial & 469 & 78.8 \\
\hline Appendicular & 126 & 21.2 \\
\hline Total & 595 & 100.0 \\
\hline
\end{tabular}

Significant difference at $95 \%$ confidence interval, $Z=13.99, \mathrm{p}<0.001$.

Among 595 skeletal lesions, 469(78.8\%) lesions in axial and $126(21.2 \%)$ in appendicular sites were found. The difference of the proportion of axial and appendicular is statistically significant.

Table -7: Lesion distribution by left and right side of the body $(n=424)$

\begin{tabular}{|l|c|c|}
\hline Side of the body & No of lesion & Percentage \\
\hline Right & 235 & 55.4 \\
\hline Left & 189 & 44.6 \\
\hline Total & 424 & 100.0 \\
\hline
\end{tabular}

Significant difference at $95 \%$ confidence interval, $\mathrm{Z}=2.218, \mathrm{p}=0.002$. Among 424 lesions, $235(55.4 \%)$ lesions on right side and $189(44.6 \%)$ on left side of the midline were found. The difference of the proportion of left and rightsided lesions is statistically significant.

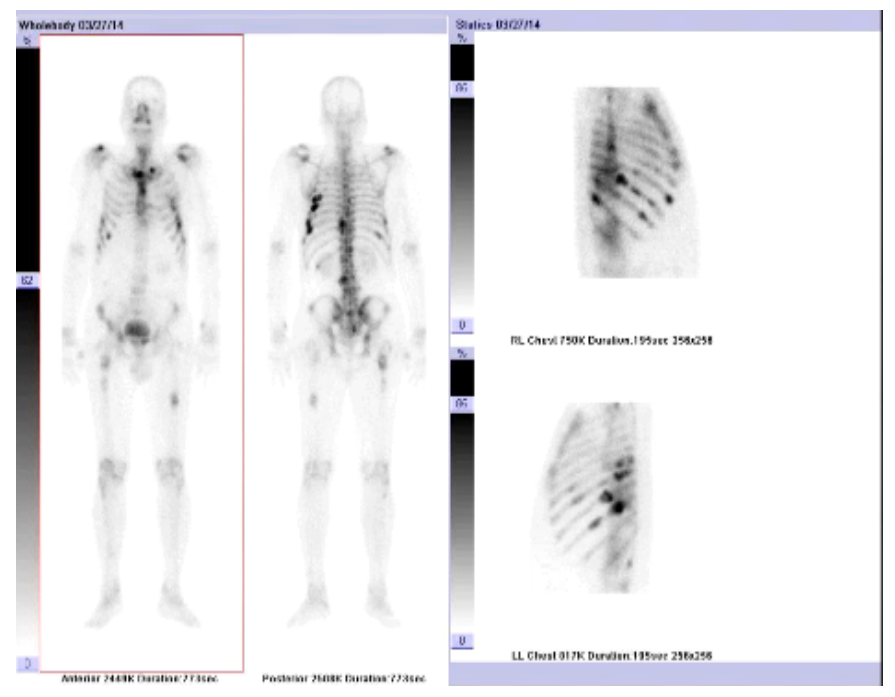

Figure 1: Extensive metastases involveing multiple ribs and verlebrae 


\section{DISCUSSION}

Bone metastasis is common in advanced cancers and causes considerable morbidity, including pain, bone fracture and disabilities. Primary malignancies originating from breast, prostate and lung were observed to be responsible for bone metastasis in almost $80 \%$ cases (2). Lung cancer is the most common male cancer and frequently has bone metastasis at presentation or during follow up, adding to both morbidity and prognostic impact $(1,2)$. The two main histo-pathologic variety of lung cancer are small cell lung cancer (SCLC) and non-small cell lung cancer (NSCLC). SCLC comprises 14\% cases of lung cancer and is poorly differentiated, rapidly growing with early metastasis. The majority of lung cancers are NSCLC. Like most cancers, treatment for limited disease is usually surgery and in advances cases, combination therapy is used depending upon the site and patient performance state. Bone metastases are diagnosed at initial presentation in 3.4 to $60 \%$ cases with NSCLC and it had been shown that up to $40 \%$ lung cancer patients with proven bone metastasis remain asymptomatic $(8,9)$.

The clinical staging at presentation of lung cancer has been performed by doing computed tomography (CT) of thorax including liver and adrenal glands, CT scan or MRI of the brain and bone scan for bone involvement. In non-small cell lung cancer bone scan is recommended at time of diagnosis to aid the staging of the disease and in selecting patients for surgical resection (10). Recently ${ }^{18}$ F-FDG PET or PET-CT is reported to have more specificity for assessing bone or soft tissue involvement for staging, although it is not using as a routine and the procedure is expensive (2, 9).

Since the introduction of technetium based scans, approximately 39 years ago, ${ }^{99 \mathrm{~m}}$ Tc MDP bone scan has been the standard imaging method for detection of bone metastases (6). Bone scan has high sensitivity and ability to examine the whole skeletal system within reasonable time. Published sensitivity rates of bone scan in detecting bone metastases vary between
$60 \%$ and $100 \%$ with a specificity of $78 \%-100 \%(10)$. In the present study the rate of metastasis was $80.5 \%$, which is higher comparing to $55.0 \%$ reported by Wang CY et al 2010 (11) and 62.5\% reported by Kakhki VR et al 2013) (12). This difference is likely due to different stages of the disease and due to different study populations.

This study showed solitary lesion in $18.2 \%$ cases and multiple site involvement in more than $77 \%$ cases. Similar findings of multiple site involvement in $80 \%$ and $90 \%$ cases were reported by Decroisette, C. 2011, Sugiura, H. 1988 and others $(13,14)$.

Distribution of bone metastases from lung cancer was reported to be more frequent in ribs followed by spines and pelvis $(1,11,12)$. This study showed similar findings with most frequent site of involvement of metastases found in the ribs (75\% cases) followed by spines (54\% cases) and pelvis (23\% cases) as shown in Figure1. Another study by Equchi K et al reported that vertebral column was the most frequent site of involvement followed by ribs and pelvis.

Our study showed the predilection of metastases to be more in the axial skeleton comparing to the appendicular skeleton. Among the 595 sites of metastatic lesions, $469(78.8 \%)$ were distributed in axial skeleton and $126(21.2 \%)$ were distributed in the appendicular skeleton. The difference between the axial and appendicular distribution was statistically significant ( $Z=13.99$, p $<0.001$ ). Wang $\mathrm{CY}$ et al. 2010 (11) reported the location of $49.6 \%$ metastases in axial skeleton and $36.0 \%$ in appendicular skeleton. In this study metastatic lesions detected on right side of body were 235 (55.4\%), which was significantly higher in number $(Z=2.218, p<0.002)$ than the lesions distributed on left side of the body, 189 (44.6\%). In contrast, Wang CY et al. 2010 found more lesions on left side of the body but this difference was not statistically significant (11). 


\section{CONCLUSION}

Bone metastasis is very common in patients with lung cancer. The predilection site for metastasis was the axial skeleton which had statistically higher involvement than appendicular skeleton. Distributions of metastatic bone lesions were higher in ribs followed by vertebrae and pelvis. Significant difference was observed in the distribution of metastasis between the right and left side of body.

\section{REFERENCES}

1. Memon AG, Jaleel A, Aftab J. Pattern of prostatic carcinoma metastasis in bones detected by bone scans using Tc-99m methyl diphosphate (Tc99m-MDP) imaging technique. Pak J Med Sci 2006; 22:180-183.

2. Galasko CSB. The anatomy and pathways of skeletal metastases. Weiss L Gilbert AH eds. Bone metastasis 1981:49-63 GK Hall Boston, MA.

3. Padhani A, Husband J. Bone metastases. In: Husband JES, Reznek RH, eds. Imaging in Oncology. Oxford, U.K.: Isis Medical Media Ltd.; 1998:765-787.

4. Hospital Cancer Registry Report 2008-2010 (printed) and 2011-2013, National Institute of Cancer Research and Hospital (NICRH) Dhaka Tribune, Published: 03:12 January 19, 2014.

5. Quint LE, Tummala S, Brisson LJ, Francis I R, Krupnick A S, Kazerooni E A et al. Distribution of distant metastases from newly diagnosed non-small cell lung cancer. The Annals of Thoracic Surgery 1996; 62: 246250.

6. LD Rybak, D I Rosenthal. Radiological imaging for the diagnosis of bone metastases. Q J Nucl Med 2001;45:5364.7

7. Ryan PJ, Fogelman I. The bone scan: where are we now? Sem Nucl Med 1995; 25:76-91.

8. Morgan JWM, Adcock KM, Donohue RE. Distribution of skeletal metastases in prostatic and lung cancer. Urology 1990; 36: 31-34.

9. Lardinois D, Weder W, Hany TF, et al. Staging of nonsmall-cell lung cancer with integrated positron-emission tomography and computed tomography. N Engl J Med. 2003; 348:2500 -2507.

10. Hamaoka T, Madewell JE, Podoloff DA, Hortobagyi GN, Ueno NT. Bone imaging in metastatic breast cancer. J Clin Oncology 2004; 22:2942-2953.
11. Wang CY, Zhan XY. ${ }^{99 \mathrm{~m}}$ Tc-MDP whole body bone imaging in evaluation of the characteristics of bone metastasis of primary lung cancer. Zhong Zhong Liu Zai 2010; 32(5):382-6.

12. Kakhki VR1, Anvari K, Sadeghi R, Mahmoudian AS, Torabian-Kakhki M. Pattern and distribution of bone metastases in common malignant tumors. Nucl Med Rev Cent East Eur 2013;16 (2):66-9.

13. Tsuya A, Kurata T, Tamura K, Fukuoka M. Skeletal metastases in non-small cell lung cancer: a retrospective study. Lung Cancer (Amsterdam, Netherlands) 2007; 57: 229-232.

14. Sugiura H, Yamada K, Sugiura T, Hida T, Mitsudomi T. Predictors of survival in patients with bone metastasis of lung cancer. Clinical Orthopaedics and Related Research 2008; 466: 729-736 